\title{
Numerical analysis of behaviour of compressed thin-walled Z- profiles weakened by holes
}

\author{
Katarzyna Falkowicz, ${ }^{1, *}$ \\ ${ }^{1}$ Faculty of Mechanical Engineering, Department of Machine Design and Mechatronics, Nadbystrzycka 36, 20-618 Lublin, Poland
}

\begin{abstract}
This paper presents the results of numerical analysis conducted to investigate compressed thinwalled Z-profile weakened by holes with variable geometrical parameters. The specimens made of constructional steel were articulately supported on the edges of the cross-section in the upper and lower parts. The FEM analysis examined the nonlinear stability of these structures in the post-buckling state, where the mode of buckling was forced to ensure their stable behaviour. The numerical computations were performed within the geometrically nonlinear range until the yield point was reached. The investigation involved determining the effect of holes sizes on allowable operational loads. Numerical analysis was conducted with the Abaqus commercial FEM software package.
\end{abstract}

\section{Introduction}

Thin-walled constructions belong to the category of loadbearing structures characterised by high strength and stiffness with a simultaneously low own weight, thus allow constructors to a great freedom to shape a construction form [1]. Given the above properties, these structures are widely applied not only in the aerospace and automotive sectors, but also in designs where low structure weight is crucial. A disadvantage of thin-walled steel or composite structures is that they are prone to loss of stability under compressive or shearing loads. This issue was described in numerous research publications [27].

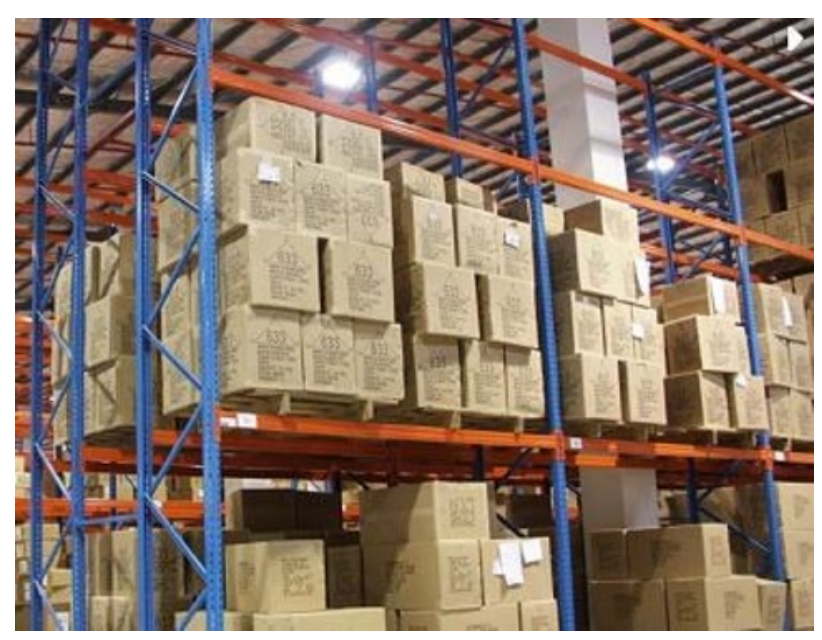

Fig. 1. Example of application of perforated elements [8].

Nonetheless, thin-walled structural elements can operate even after their stability loss, provided that they do it in the elastic range [9-11].
Thin-walled Z-section profiles are currently quite widely used and quite often weakened by holes to reduce their volume. An example of such elements are perforated profiles used, among others for shelves, balustrades etc. One example of popular design solutions based on the use of openwork beams as load-carrying structures is shown in figure 1.

Perforated Z-section profiles provide a rigid and strong construction as well as cost savings associated with weight reduction. Common methods of increasing the carrying capacity of a structure are often associated with increase in weight of a structure due to introduced modifications. Currently, there is a need for structural solutions which ensure that the weight of the profile is either similar or-more preferably- lower than the primary weight, and that the profile has holes with geometry that influences on stress concentration and enhances its performance properties.

The issues of stability, post-critical behaviour and load-bearing capacity of profiles with holes have been described, i.a. in the works [12-15].

Considering the demand for solutions ensuring higher operational properties of the structure, it is justified to check such profiles for behaviour under the influence of critical loads.

The subject described in the present work are a thinwalled Z-profiles made of steel and weakened by holes. The scope of the research included the linear and nonlinear issue of stability of the $\mathrm{Z}$-profiles subjected to uniform compression. A commercial ABAQUS program [16] was used to develop a discrete model and perform calculations, using the finite element method [17], which currently has a very wide application [18-24]. The FEM analysis examines the nonlinear stability of these structures in the post-buckling state, where the mode of buckling is forced to ensure their stable behaviour. The

${ }^{*}$ Corresponding author: k.falkowicz@pollub.pl 
investigation involves determining the effect of holes sizes on allowable operational loads. The numerical computations are performed within the geometrically nonlinear range until the yield point is reached.

\section{Research subject and methodology}

The research was made for thin-walled Z-section profiles with varying hole diameters and with constant cross section. The tested structures have been assigned to the properties of constructional steel S250GD hot-dip galvanised. This steel has recently become popular in perforated profiles. The material properties are presented in Table 1.

Table 1. Material properties of steel S250GD[25].

\begin{tabular}{|c|c|c|}
\hline \multicolumn{3}{|c|}{ S250GD steel } \\
\hline Property & Unit & Value \\
\hline $\begin{array}{c}\text { Young } \\
\text { Modulus [E] }\end{array}$ & $\mathrm{MPa}$ & 210000 \\
\hline $\begin{array}{c}\text { Poisson's } \\
\text { Ratio [v] }\end{array}$ & - & 0.3 \\
\hline $\begin{array}{c}\text { Yield Point } \\
\text { [Re] }\end{array}$ & $\mathrm{MPa}$ & 250 \\
\hline $\begin{array}{c}\text { Yield } \\
\text { Strength } \\
{[\text { Rm] }}\end{array}$ & $\mathrm{MPa}$ & 330 \\
\hline $\begin{array}{c}\text { Elongation } \\
{[\mathrm{A}]}\end{array}$ & $\%$ & 19 \\
\hline
\end{tabular}

In all examined cases, the Z-profile had the same overall dimensions presented in Fig. 1a, with length/height $H=200 \mathrm{~mm}$. The element was modelled as a shell element with a nominal thickness of $2 \mathrm{~mm}$. The hole diameters were changed in a range from $5 \mathrm{~mm}$ to $15 \mathrm{~mm}$, at every 5 $\mathrm{mm}$. The distance between the centres of the holes was set to $20 \mathrm{~mm}$. The 3D model of an openwork profiles with holes are shown in Fig. $1 \mathrm{~b}$. The simulations were performed for three variable cases of hole.

The investigation involved performing numerical analysis of non-linear stability of compressed Z-profiles, where first mode of buckling was forced to ensure stable operation of this structure in the post-buckling state. The Z-profiles had a few holes, the geometric dimensions of which had a direct effect on the profile's stability and operation in the post-buckling state. As a result, they affected the characteristics of the profiles' post-buckling equilibrium path in the elastic state. This way of shaping elastic properties of Z-profiles is particularly important if such structures are to be used for various designs.

Owing to considerable displacements that occurred when the element was under load, numerical analysis also involved solving the problem of geometric nonlinearity using the Newton-Raphson method, an iterative algorithm for determination of approximate values of elements of functions describing a given problem [26].

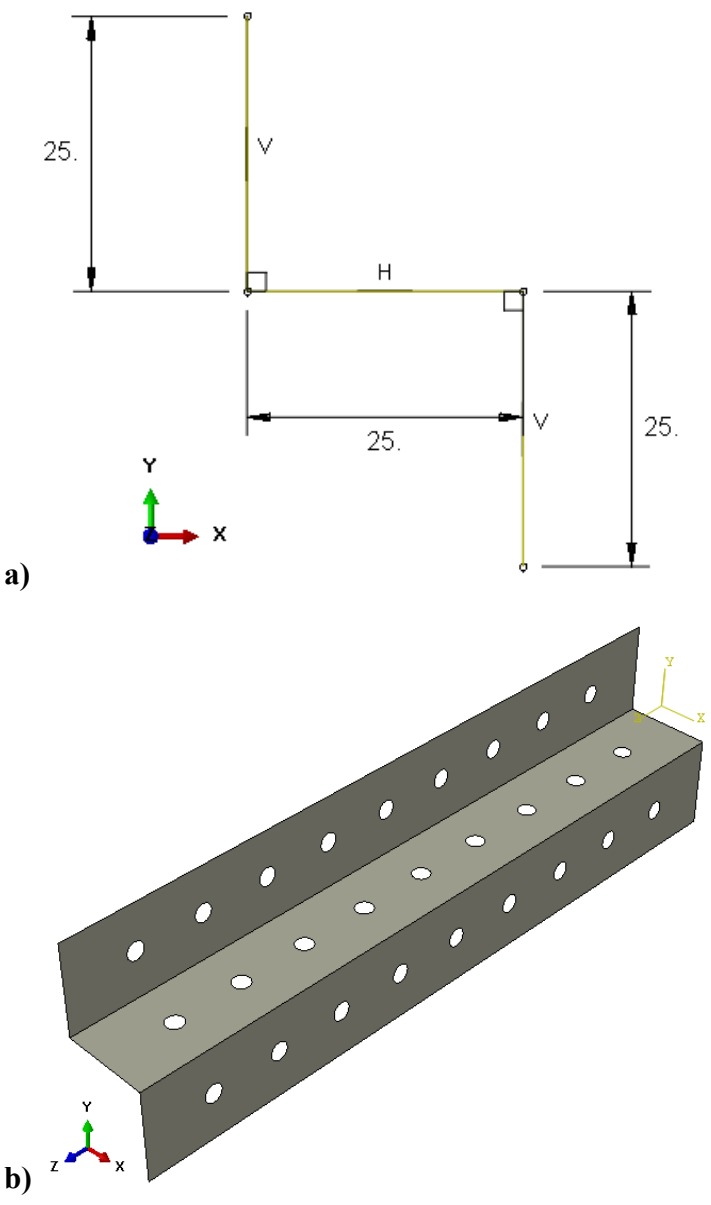

Fig. 2. Numerical model a) cross sectional geometry of profile, b) $3 \mathrm{D}$ element with length of $200[\mathrm{~mm}]$ and hole $5[\mathrm{~mm}]$.

The numerical analysis was performed using the FEbased commercial software ABAQUS ${ }^{\circledR}[16]$.

\section{Numerical analysis}

The discretisation of the tested Z-profile was made using the four-node reduced integration shell elements (S8R), each element having six degrees of freedom at every node. Fig. 3 shows the general view of the numerical model of the structure.

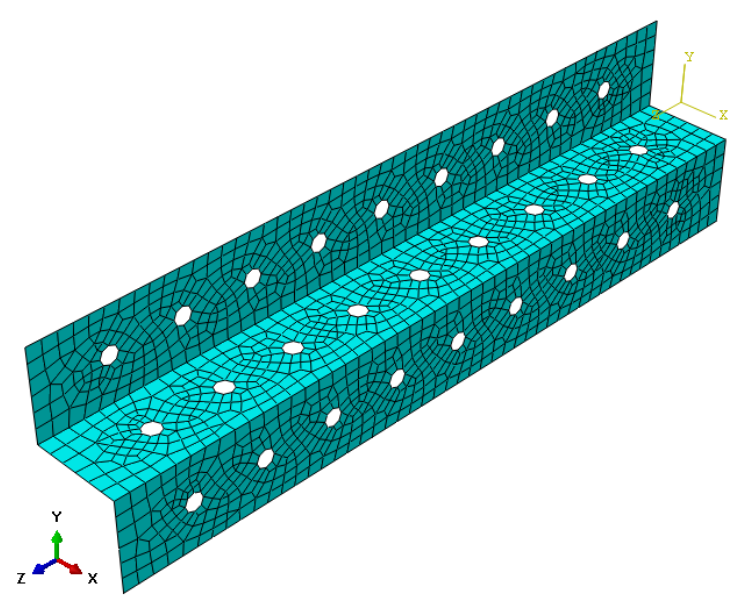

Fig. 3. Discrete model of Z-section profile. 
The boundary conditions of the numerical model which plotted the articulated support of the profile were defined by blocking the kinematic degrees of freedom of the nodes located on the upper and lower edges of the profiles to ensure correct modelling of the structure's behaviour at buckling (Fig.4). The FEM model was loaded by applying uniform load to the upper edge of the profile.

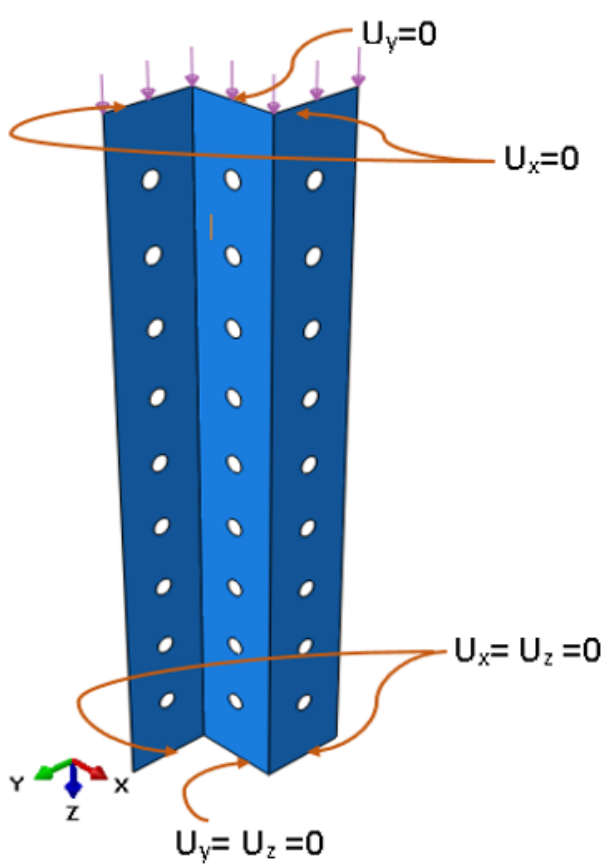

Fig. 4. Boundary conditions of the numerical model.

To maintain proper elasticity of the element, the numerical computations were performed only until the moment when the metal exceeded its yield stress at $\mathrm{Re}=250 \mathrm{MPa}$.

The numerical models prepared in this way were used for initial FEM analysis in order to define the critical state for all tested samples. The numerical computations were run in two stages. The first stage involved described critical load for all tested samples. The second stage of the computations involved solving the problem of nonlinear stability. This stage involved the examination of displacements and stresses in relation to critical loads defined as a result of structure buckling.

\section{Results}

As already mentioned before, numerical calculations were carried out in two stages. The first stage was an analysis of the critical state of the structure by using a linear stability analysis - "buckling analysis", which allowed to determine the critical loads of the compressed element and the corresponding buckling forms. The second stage of calculations was to solve the problem of nonlinear stability, where the calculations were carried out on a model with the initiated geometric imperfection corresponding to the first form of buckling of the structure.
The performed numerical calculations provided the basis for the designation of the critical forces in the analysed cases (Tab.1).

Table 2. Critical loads depending on hole diameter.

\begin{tabular}{|c|c|}
\hline & Buckling load $[\mathrm{N}]$ \\
\hline Diameter $5[\mathrm{~mm}]$ & 147955 \\
\hline Diameter $10[\mathrm{~mm}]$ & 120097 \\
\hline Diameter $15[\mathrm{~mm}]$ & 75776 \\
\hline
\end{tabular}

For better visualisation in Fig. 5 are presented buckling modes for all studied cases.

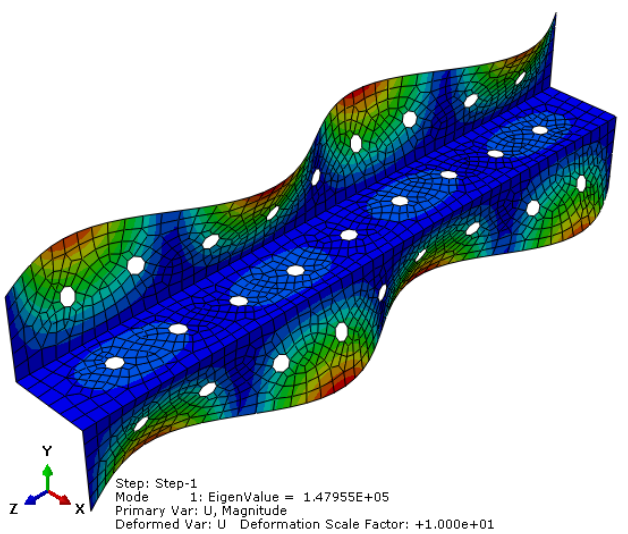

a)

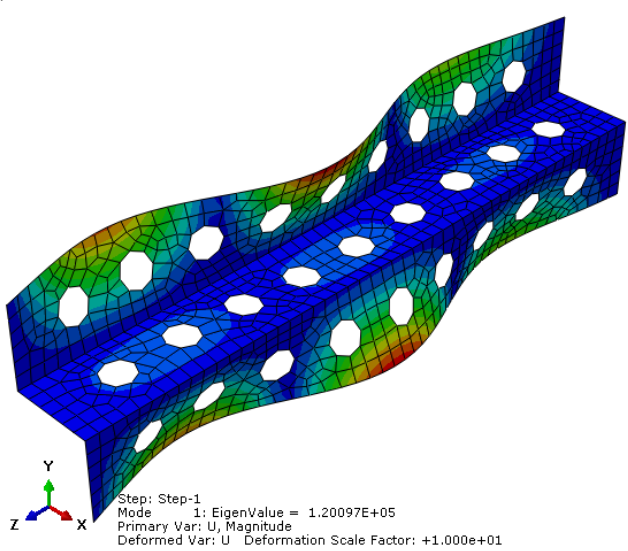

b)

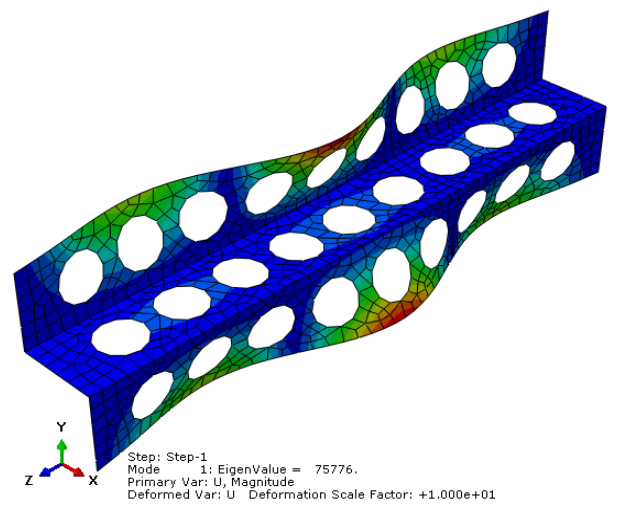

c)

Fig. 5. Buckling mode for hole diameter: a) 5 [mm], b) $10[\mathrm{~mm}]$, c) $15[\mathrm{~mm}]$ 
The profile with $5 \mathrm{~mm}$ diameter holes has a critical load of $147955 \mathrm{~N}$, while for the profile with hole diameter of $15 \mathrm{~mm}$ the load decreases to $75776 \mathrm{~N}$, which is by about $48 \%$.

The main advantage of using larger diameter holes in perforated profiles is that this have an influence on reduced material volume and specific weight, but this is not always accompanied by a higher carrying capacity. The final stage of the FEM analysis was to obtain results describing post-critical behaviour of the structure. The examination of the post-critical state included also determination of post-critical equilibrium paths. The results of loads and displacements make it possible to determine the stiffness and work of the structure. The relations describing deflexion of the profile caused by $\mathrm{Z}$ axis compression and the load increase on deflexion help to describe the behaviour of these structures under load up to the yield point.

Fig. 6 shows the post critical equilibrium paths for varying hole diameters.

The obtained results of numerical calculations allow also to make a qualitative and quantitative assessment of the construction work in the post-critical range.

The results of post-critical equilibrium paths describe behaviour of profiles under applied loads in accordance with the data given in Table 2 . The profiles with $5 \mathrm{~mm}$ diameter of holes are stiffer than profiles with holes with diameters of 10 and $15 \mathrm{~mm}$. Depending on the requirements, the rigidity or power consumption of the structure can be increased.

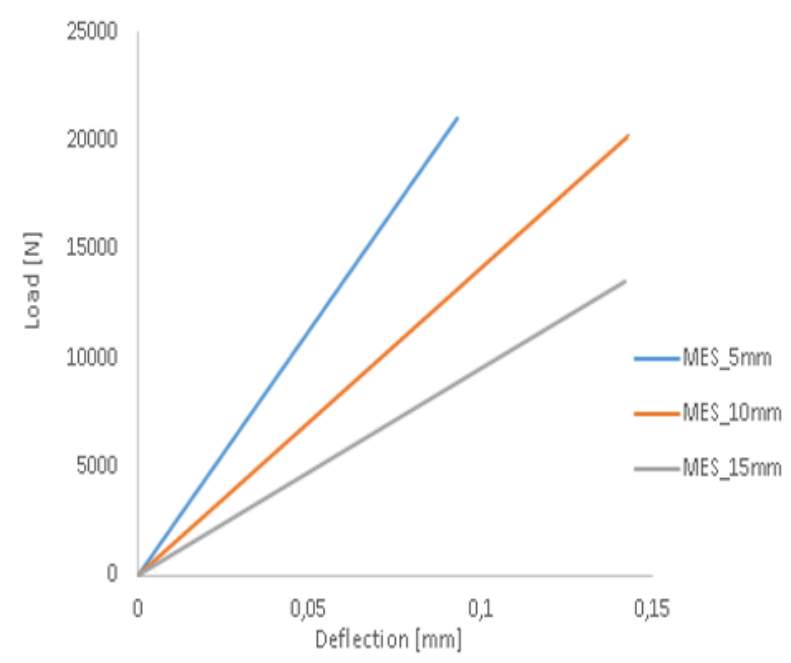

Fig. 6. Post-critical equilibrium paths in depending on hole diameter.

Fig. 7 shows the plot of reduced stress determined using the Huber-Mises-Hencky (H-M-H) hypothesis for the load that causes reaching the stress level which corresponds to the yield point and for individual stress state components.

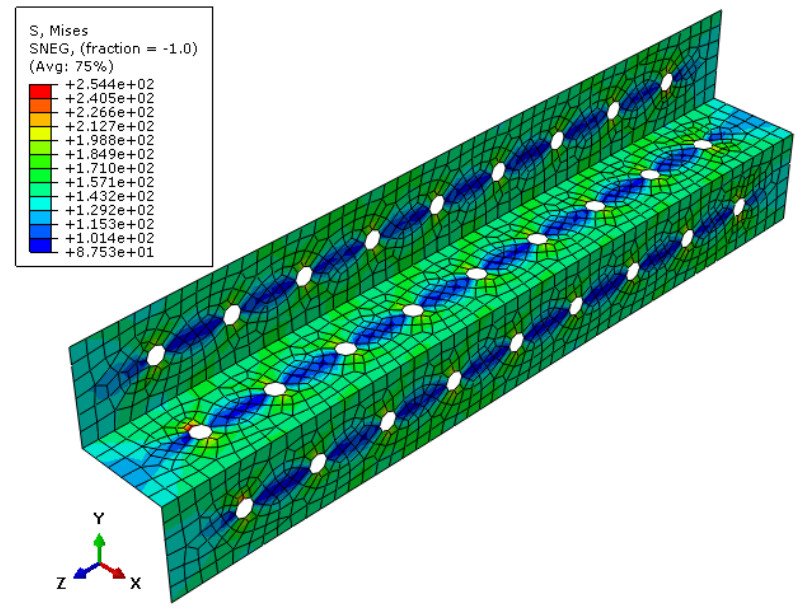

a)

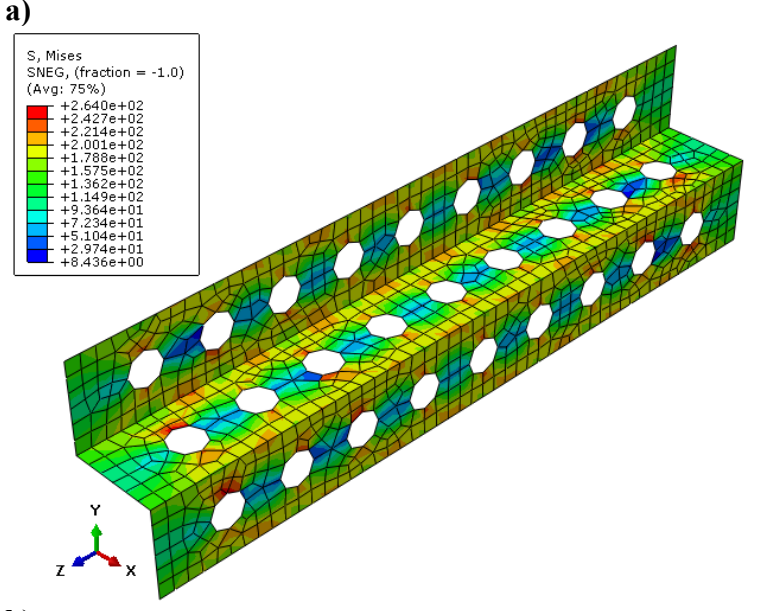

b)

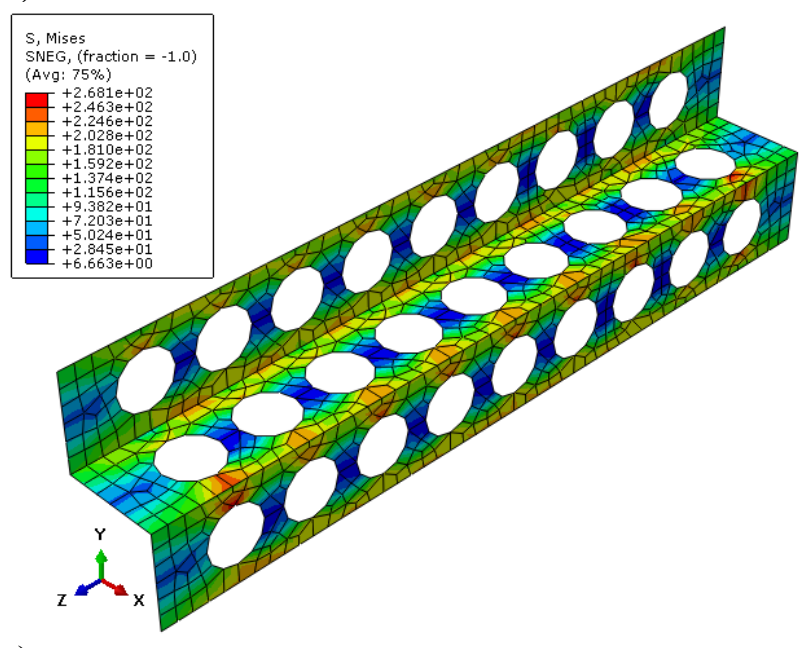

c)

Fig. 7. Distribution of reduced stress for Z-profile with hole: a) 5 [mm], b) $10[\mathrm{~mm}]$, c) $15[\mathrm{~mm}]$.

In the figure above, it can be seen that the highest stress concentration is distributed symmetrically on the edges of the holes. Increasing the diameter of holes in the profiles, leads to changes in place of concentration of the highest stresses.

\section{Conclusions}

The paper presented numerical analysis of non-linear stability of steel Z-section profiles weakened by holes, subjected to compression. The FEM analysis results 
helped to determine the effect of variations in the diameter of the profile holes on the critical loads of the models.

The presented results of the conducted research allowed to make a qualitative and quantitative assessment of the construction work in the critical and post-critical range.

The results of FEM analysis facilitated determination of the effect of changes in holes diameter of the tested profiles to critical loads. The essence of this study was to determine the effect of changing the holes diameter of thin-walled steel Z-profiles on the carrying capacity of these profiles.

The operational reliability of thin-walled structures can be increased by adjusting the holes diameter, depending on whether we want to produce profiles with higher stiffness or profiles which absorb the energy generated by the loads.

The results led to the formulation of the following conclusions:

- increasing the diameter of holes in perforated profiles leads to reduction the size of the critical load,

- the maximum stresses described by the yield point $(\mathrm{Re}=250 \mathrm{MPa})$ are concentrated near the holes edges,

- increasing the diameter of holes in the profiles leads to changes the place of concentration of the highest stresses.

The FEM results show great possibilities of observation and accurate examination of deformations, as well as determination of correct operating parameters of thin-walled profiles for the full load range.

Numerical analysis is a powerful tool for testing the load capacity and strain of thin-walled constructions subjected to specific loads.

The above conclusions have a practical significance in the aspect of calculating this type construction for applications as load-bearing elements.

\section{References}

1. F.C. Cambell, Manufacturing Technology for Aerospace Structural Materials (Elsevier, 2006)

2. Z.P. Bazant, L. Cedolin, Stability of structures. Elastic, inelastic, fracture and damage theories (Oxford University Press, 1991)

3. K. Falkowicz, ACE, 63,4, 161-172 (2017)

4. D. Banat, R.J. Mania, Thin Wall Struct., 122, 52-63 (2017)
5. D. Banat, R.J. Mania, Compos Part B Eng. 112, 278 289 (2017)

6. P. Wysmulski, A. Teter, H. Debski, AIP Conference Proceedings 1922, 080008 (2018)

7. P. Rozylo, Archives of Material Science and Engineering 84, 58-64 (2017)

8. http://tomprofil.eu/index.php/zetownik-perforwany

9. P. Rozylo, H. Debski, P. Wysmulski, K. Falkowicz, Compos. Struct. 204, 207-216 (2018)

10. Z. Kołakowski, A. Teter, Compos Struct, 129, 1-7 (2015)

11. T. Kopecki, P. Mazurek, JTAM 51, 4, 969-977 (2013)

12. K. Falkowicz, H. Debski, A. Teter, AIP Conference Proceedings 1922, 080004 (2018)

13. R. Narayanan, F.Y. Chow, Thin Wall Struct, 2,2, 241-264 (1984)

14. D. Ouinas, B. Achour, Comp. Part B 55, 575-579 (2013)

15. K. Dinesh, S.B. Singh, Compos. Struct. 92, 769-779 (2010).

16. Abaqus HTML Documentation

17. E. Rusinski, J. Czmochowski , T. Smolnicki, Advanced Finite Element Method in stability construction (Wroclaw University of Technology Press (in Polish, 2000)

18. J. Gajewski, P. Golewski, and T. Sadowski, Compos. Struct, 159, 589-599 (2017)

19. J. Gajewski and T. Sadowski, Comput. Mater. Sci., 82, 114-117 (2014)

20. R. Karpinski, L. Jaworski, M. Szala, M. Manko, ITM Web of Conferences 15, 07006 (2017)

21. R. Karpinski, L. Jaworski, J. Zubrzycki, Adv. Sci. Technol. Res. J. 10, 31, 240-246 (2016)

22. N. Kepczak, W. Pawlowski, L. Kaczmarek, Arch Metall Mater, 60, 2 (2015)

23. G. Fedorko, V. Ivanco, Procedia Engineering 48, 123-128 (2012)

24. G. Fedorko, V. Molnar, ASTRJ 11, 2, 220-225 (2017)

25. http://kbhakord.pl/pl/stal-informator-techniczny

26. H. Dębski, T. Kubiak, A. Teter, Compos Struct 100 , 195-204 (2013) 